\title{
Health Concerns of Perimenopausal Women
}

\author{
Pen-Hsin $\mathrm{Hou}^{1,2}$ \& Lee-Ing Tsao ${ }^{1}$ \\ ${ }^{1}$ Department of Nursing, National Taipei University of Nursing and Health Sciences, Taipei, Taiwan \\ ${ }^{2}$ Department of Nursing, Mackay Junior College of Medicine, Nursing and Management, Taipei, Taiwan \\ Correspondence: Prof. Lee-Ing Tsao, Department of Nursing, National Taipei University of Nursing and Health \\ Sciences, No.365, Ming-te Road, Peitou District, Taipei City, Taiwan. Tel: 886-2282-2710.
}

Received: February 14, 2020

Accepted: February 28, 2020

Online Published: March 17, 2020

doi:10.20849/ijsn.v5i1.727

URL: https://doi.org/10.20849/ijsn.v5i1.727

\begin{abstract}
Background

Practicing perimenopausal health promotion is an important key stage for the healthy life of the coming elderly. However, there are few studies conducted on these women's subjective health concerns. Getting insight into their health concerns can help women implement their own health promotion lives.
\end{abstract}

Aims

The goal is to generate data from the in-depth interview for perimenopausal women based on their perceptions, beliefs, values, and feelings regarding perimenopausal women's subjective health concerns.

Methods:

The qualitative research by using content analysis was applied. In-depth interviews were conducted with 19 perimenopausal women with a mean age of 51.31 years. The constant comparative method was used to analyze the interview data.

Results

Two themes and their subthemes were identified: (a) "Evaluating Health" - "Suspecting a menopausal disease or illness", "Easily feel tired, lack energy, and feel not as strong as before", "Worried about my abnormal physiological data" and (b) "Remaining Young" - "Worried that I lost my female characteristics and reproductive function", "Weight loss is the focus of life, but it is not easy to achieve."

Conclusion

"Evaluating Health" and "Remaining Young" are two health concerns for perimenopausal women. It is crucial for health providers to advocate these two concerns as slogans for perimenopausal health promotion women.

Keywords: perimenopausal, women, health concerns

\section{Introduction}

Against the background of aging populations, the population of middle-aged and older women has been growing. According to a World Health Organization report (WHO,2019), the global life expectancy for women was 74.2 years in 2019, and the global population of perimenopausal women was expected to exceed 1.2 billion by 2030 . Menopause is a point in time 12 months after a woman's last period (National Institutes of Health[NIH],2017). The WHO (1996) divides the change in a woman's menstrual cycle into three stages. Premenopause is the time period of fertility before menopause; in this period, the menstrual cycle remains regular. During perimenopause, a woman experiences endocrine and physiological changes, clinical symptoms that signal the imminence of menopause, and irregular menstrual cycles; perimenopause ends 1 year after menopause occurs. Postmenopause starts 1 year after menopause occurs. Perimenopause is a transition period that can occur 5-10 years before menopause (Gracia \& Freeman, 2018), lasts for an average of 7 years and a maximum of 14 years, and typically occurs between the ages of 45 and 55 years (NIH, 2017). The menopausal transition features irregular menstrual cycles, hot flashes, and night sweats. After menopause, women mainly experience genitourinary symptoms, including vulvovaginal atrophy and lower-urinary-tract symptoms, such as frequent urination, urgent urination, and nocturia (Takahashi \& Johnson, 2015). Additionally, women's overall quality of life might be negatively affected by metabolic disorders and physical and emotional states associated with perimenopause, including 
weight gain; increased visceral, subcutaneous, and abdominal fat; impaired glucose tolerance; hyperinsulinemia; hypertension; sleep disorders; fatigue; and sexual discomfort (Marlatt, Beyl, \& Redman, 2018). Women in perimenopause also experience changes in their skin, mucous membranes, hair, and musculoskeletal systems (Monteleone, Mascagni, Giannini, Genazzani, \& Simoncini, 2018). According to Parand, Mosalanejad, Ramezanli, and Ghavi (2014), during perimenopause, women may experience social, biological, and psychological crises; exhibit volatile emotions and moods; change their self-concept because of changes in their appearance and self-efficacy; exhibit negative attitudes toward others and reduced enthusiasm because of diseases and reduced capabilities; dissociate themselves from interpersonal relationships; experience changes in their marital relationships; and exhibit a higher incidence rate of mental and physical diseases than do women of other age groups. Perimenopausal status increases the risk of depression (Lin, Hsiao, Liu, \& Chang, 2013). An increasing body of evidence has defined perimenopause as a complex phenomenon, and each woman's experience in this stage of life is determined by her decisions regarding experiencing perimenopause as well as her cultural concepts, values, and attitude toward it (Hoga, Rodolpho, Goncalves, \& Quirino, 2015).

Women experience constantly changing physical and psychological states in perimenopause; however, their primary health concerns during this period have not yet been clarified by research. Therefore, the present study adopted a qualitative interview approach to evaluate perimenopausal women's health concerns, which could provide insights into the development of health care strategies specifically for women in perimenopause.

\section{Method}

\subsection{Research Design}

This study employed a qualitative descriptive method to collect data on the health concerns of women in perimenopause and conducted a qualitative content analysis to analyze the collected data. Qualitative descriptive method involves naturalistic inquiry, which emphasizes research on a phenomenon in its natural state and obtains the most intuitive and pure answers to questions. A qualitative descriptive method is the most suitable approach for studies aiming to obtain the most direct description of the research participants (Ding, Bai, Ma, Zhu, Kong, \& Jiang, 2018; Sandelowski, 2000).

\subsection{Participants}

This study adopted purposive sampling and recruited 45-60-year-old women who perceived themselves to be in perimenopause or had experienced menopause, lived in northern Taiwan, and were willing to share their experience of perimenopause to be research participants. Those who had surgical menopause or severe illnesses were excluded because illnesses might affect their health concerns. To form a representative group of participants, 19 women of different ages, educational attainments, occupations, and marital statuses were recruited for interviews. Data saturation occurred at the 16th interview. The remaining three interviews were conducted to ensure that no new categories emerged.

\subsection{Data Collection}

Data collection was conducted using snowball sampling after passing a review by the Institutional Review Board of Mackay Memorial Hospital. Participants were fully informed of the research purpose before providing written informed consent and being invited to a one-on-one interview in a room separated from interruptions, such as a conference room or office. To explore women's health concerns in the interviews, participants were asked questions such as "What health problems concern and trouble you the most? Why?" and were prompted to elaborate with questions such as "Do you mean...?" and "Can you talk more about it?" After the interviews, participants were asked if they had anything else they wish to add to ensure that the data collected were complete. All interviews were audio-recorded with the participants' consent and transcribed within 1 week. During the interviews, participants were reminded of their right to terminate the interviews or withdraw their participation in the study at any time. Each interview lasted approximately 35 to 60 minutes, and data were collected between June 2018 and February 2019 until theoretical saturation was reached.

\subsection{Data Analysis}

The collected data were analyzed using inductive content analysis proposed by Graneheim and Lundman (2004). Interviews and data analysis were conducted concurrently. First, the interview transcripts of all participants were read multiple times before all contents related to their health concerns were extracted and combined into one text, which constituted the unit of analysis. This text was divided into several meaning units, compressed, and coded. Subsequently, the codes were classified into categories according to their similarities and differences. After relationships between categories became clear, an expert in qualitative analysis was invited to review and verify the categories according to the text and concepts. Finally, themes were derived from the latent meanings of 
categories (Graneheim \& Lundman, 2004).

\subsection{Rigorousness}

By employing a qualitative design, the rigorousness of the study's data collection and analysis was assessed by using the four aspects of trustworthiness proposed by Lincoln and Guba (1985): credibility, transferability, confirmability, and dependability. Purposive sampling was adopted to recruit women who perceived themselves to be in perimenopause or had experienced menopause as research participants; additionally, this study selected women of different ages, educational attainments, occupations, and marital statuses to increase its transferability. Credibility was achieved by collecting data using snowball sampling. A satisfactory trusting relationship was developed between the authors and participants to learn their actual experiences. To ensure confirmability, the interviewers maintained a neutral attitude in interviews and did not criticize the participants for their comments to ensure that the participants could freely speak about their experiences. The interview transcripts remained complete and unaltered. To ensure the dependability of findings, another expert in menopause research and qualitative studies was invited to verify random parts of each analysis document.

\section{Results}

\subsection{Sample Characteristics}

A total of 19 women in either perimenopause or menopause were interviewed. They averaged 51.31 years old and had educational attainments ranging from senior high school to $\mathrm{PhD}$. Five participants were unmarried and one was divorced; seven were in perimenopause and 12 were in menopause.

\subsection{Evaluating Health" and "Remaining Young}

Perimenopausal women's primary health concerns were "evaluating health" and "remaining young." Evaluating health refers to women becoming attentive to their health status because they were aware of their changing physical and mental states. Remaining young denotes that perimenopausal women became concerned about whether they still appeared young after they were no longer fertile and noticed changes in their physical appearance. The themes and subthemes were shown in Table 1.

Table 1. Health concerns, the themes and subthemes

\begin{tabular}{ll}
\hline Theme & Subtheme \\
\hline Evaluating Health & Suspecting a menopausal disease or illness \\
\cline { 2 - 2 } & Easily feel tired, lack energy, and feel not as strong as before \\
\cline { 2 - 2 } & Worried about my abnormal physiological data \\
\hline Remaining Young & Worried that I lost my female characteristics and reproductive function \\
\cline { 2 - 2 } & Weight loss is the focus of life, but it is not easy to achieve \\
\hline
\end{tabular}

\subsubsection{Evaluating Health}

This theme comprised the following subthemes: suspecting a menopausal disease or illness, easily feeling tired, lacking energy, and feeling weaker than before, and worrying about abnormal physiological data.

\subsubsection{Suspecting a Menopausal Disease or Illness}

This subtheme describes the women's distress caused by difficulties they faced in daily activities and their physical and mental state in perimenopause; the women were unsure if such conditions resulted from illnesses or perimenopause.

"I first couldn't sleep well and then could barely move my arms; I couldn't raise them up. That hurt a lot; I felt like I was going to die." (D)

"I wake up covered in sweat almost every day and often feel dizzy in the morning, like the world is spinning. I never know when I'll wake up feeling dizzy, and I can't control my sweating either." $(G)$

"I thought I was depressed at that time because I was overly emotional all the time, felt down, and couldn't sleep at night." (C)

3.2.1.2 Easily Feel Tired, Lack Energy, and Feel Not as Strong as Before

This subtheme refers to the women presenting reduced physical capacity and worsened psychological state than 
before.

"II feel old and physically can't do what I want to do. I used to do chores and manage to finish some other tasks after getting home from work. Now I feel extremely tired only from working." (B)

"After 50 when menopause occurred, you would notice a large decline in your physical activity, walking, muscles, and heartbeats. The decline was too fast." (H)

"[My] arms pop when I try to raise them. [My] knees also pop when I squat down. They don't hurt, but there's this popping sound in the joints. [I feel like I'm] becoming a robot." (A)

"I feel like my memory and eyesight have declined, particularly my eyesight. It becomes demanding when I try to see [certain] things." (E)

\subsubsection{Worried About My Abnormal Physiological Data}

This subtheme indicates that the women were worried about abnormal physiological results obtained using medical instruments.

"I feel like I get high blood pressure every time I stay up a bit late or have a headache...I'm scared of having a stroke. [I'm] scared that I will have no one to take care of me." (B)

"I have high blood lipids. After I gained weight, my blood lipid levels started to change, so I always keep an eye on it." (E)

"My watch measures my blood pressure. Ever since I found out about my hypertension, I have been worrying [about my health]." (F)

"I was diagnosed as having osteoporosis in a physical check-up. I found out about it from a bone mineral density test included in the check-up conducted the year before last year. The readings I got last year were worse than those from the year before." (T)

\subsubsection{Remaining Young}

This theme comprises subthemes of "worrying about losing female characteristics and reproductive function" and "Weight loss is the focus of life, but it is not easy to achieve"

\subsubsection{Worried That I Lost My Female Characteristics and Reproductive Function}

"In terms of childbirth, you would feel strongly about, after menopause, the loss of your role as a female attributed by your hormones. It feels like you have lost your role before you can accomplish your mission in this role..." (B)

"I get scared a bit. I'm worried. I feel like maybe I'm now 'less like a woman."” (H)

"People used to call me miss when I shopped in traditional markets. Now they call me dajie (literally older sister in English). I still can't bring myself to accept this." (L)

"Because my roommate and I are both unmarried, we particularly care about being called 'ou ba sang' (literally old lady in English). We really do care; do we really look that old?" (J)

3.2.2.2 Weight Loss is the Focus of Life, But It Is Not Easy to Achieve

"Girls want to be pretty, but I have gained six kilograms over the one and a half years since my menopause. I weighed 58 kilograms, and now I weigh almost 66. My physical appearance has been affected considerably, and I've been looking for ways to lose weight." (G)

"I didn't easily gain weight. I gained only one or 2 kilograms after I gave birth to my child and had kept my body shape for more than 10 years since. Then in the last 1 or 2 years, I gained about 10 kilograms and can't seem to lose them." (P)

\section{Discussion}

This study conducted qualitative interviews to identify the health concerns of 19 women in perimenopause or menopause. According to the data analysis, evaluating health and remaining young were the underlying themes of these women's health concerns. These themes reflected their awareness of aging, and their physical functions had deteriorated as they aged (Strehler \& Mildvan, 1960).

Perimenopausal syndrome manifests in physical ailments, results in an unignorable deviation from healthy status, and makes women doubt their health status. According to a systematic literature review, perimenopausal symptoms among Asian women are primarily physical and somatic, such as muscle and joint pain or discomfort, lower back pain, waist soreness, headache, insomnia, sleeping disorders, heart discomfort, impaired memory, 
and reduced physical capacity (Islam, Gartoulla, Bell, Fradkin, \& Davis, 2015). A Japanese study revealed that among the most common perimenopausal symptoms, fatigue was the second only to stiff shoulders (Ishizuka, Kudo, \& Tango, 2008).

Concern about abnormal physiological data has been rarely discussed in studies. Although studies have verified the effect of perimenopause on the cardiovascular and skeletal systems (Greendale et al., 2019; Samargandy et al., 2020), few studies have explored women's subjective concerns about their physiological results. Additionally, the present study demonstrated that intelligent wearable devices revealed physical abnormalities to these women. The international research and advisory company Gartner predicted that spending on wearable devices would grow by $27 \%$ from 2019 to 2020 (Gartner, 2019), indicating the high acceptance of technological products among people in the contemporary era. The increased availability of physiological parameters might enhance women's proactivity in self-monitoring their health. However, monitoring many other physiological data, such as bone mass density and blood lipid levels, still relies on physical examinations in medical institutions. The women in this study can easily refer to their health reports during the interviews, which was made possible by the comprehensive health insurance system in Taiwan. In Taiwan, every person older than 40 years can receive a free health examination every 3 years; the examination includes blood and biochemical tests, a kidney function test, and a health consultation (Health Promotion Administration, Ministry of Health and Welfare [MOHW-HPA], 2017). Relatively affordable and convenient medical services enable women to easily obtain various physiological data, which became the focus of their concerns in perimenopause.

Remaining young was the other aspect of health that concerned these women and mainly pertained to the deterioration of their fertility and changes in their appearance. Changes in body image were the focus of their concerns; in particular, changes in physical appearance and functions changed how the women viewed and felt about their bodies (Pearce, Thogersen-Ntoumani, \& Duda, 2014). Many perimenopausal women have an impaired body image because they consider themselves to be no longer attractive (McKinley \& Lyon 2008). Ginsberg et al. (2016) demonstrated that of 75256 menopausal women, 83\% were dissatisfied with their bodies; they weighed more than they expected, and their distribution of fat had changed after menopause to be concentrated in the abdominal region (Ambikairajah, Walsh, Tabatabaei-Jafari, \& Cherbuin, 2019). In perimenopause, changes in body weight and shape indicate that women may fail to achieve the ideal slim, young, and beautiful body promoted by the media (Luff \& Gray, 2009). Moreover, the skin is considerably affected by perimenopausal hormonal changes, which reduce the skin's collagen content, water content, elasticity, thickness, and the overall quality (Reus, Brohem, Schuck, \& Lorencini, 2019). Appearance changes including wrinkles and white hair constitute the social image of old age. Titles associated with such an image often upset perimenopausal women. Titles are used to address someone with reference to their particular role, status, or occupation and pertain to a society's culture (Yang, 2003). People's perceptions of titles vary by individual and regional differences. For example, "ou ba sang" is used in Taiwan to address a middle-aged or older woman and typically has a disapproving connotation; "dajie" is used to address a woman older than the speaker. Therefore, menopausal women feel hurt when they hear others address them as "ou ba sang" or "dajie" because they are made aware that they are no longer considered young by others.

Reyhani, Kazemi, and Keshvari (2018) investigated changes in middle-aged women's fertility and revealed "fall" to be a primary category, which was related to women's perception of weakened femininity and gender roles as well as the loss of youth. Women in the study were anxious about changes in their fertility and gender role; a demographic analysis revealed that unmarried women felt more strongly about such changes. Studies have indicated that married women are healthier overall and present relatively minor perimenopausal symptoms compared with single women possibly because married women have stronger social relationships and family support (Namazi, Sadeghi, \& Behboodi Moghadam, 2019). However, Reyhani et al. (2018) reported that women who established their identity and personality based on motherhood and sexual partnership felt disheartened after encountering declined fertility in middle age possibly because such a change in their fertility ended the dominant position created by their gender roles (Brown et al., 2015). Thus, unmarried women in my study who had never obtained such roles or identity through childbirth or being a mother could relate more to the loss of fertility and gender roles. In addition to growing older, a common emotional conflict in perimenopause is the fear of death (Adler et al., 2000). In the present study, participant B mentioned, "[I am] scared that I will have no one to take care of me," and participant A was "worried about dying alone." According to these responses, the present study inferred that unmarried women who lost their fertility were worried about being uncared for in old age. In Chinese ethnic culture, children are responsible for caring for their parents as they age and after they are deceased (Ko, 2006); as these women experienced deteriorated physical functions and ailments in perimenopause, they became worried about their life in late adulthood. 


\section{Conclusion}

The results of the study indicated that the two main health concerns, "evaluating health" and "remaining young," are core values for perimenopausal women. Regarding "evaluating health," women exhibited behaviors of suspecting a menopausal disease or illness, easily feeling tired, lacking energy, and feeling weaker than before, and worrying about abnormal physiological data. Regarding the other health concern of remaining young, women worried about losing their female characteristics and reproductive functions and weight loss is the focus of life, but it is not easy to achieve.

The subjective health concerns among these women refer to their worries about their health uncertainty and aging at this stage. Health providers must advocate for these two concerns to promote perimenopausal health in women.

\section{Study Limitation and Recommendation}

In this study, data saturation was achieved with a sample of 19 participants. The sample was limited to participants living in northern Taiwan, and the results cannot be generalized to all patients in Taiwan. However, this study focused on perimenopausal women's health concerns from the women's subjective perspectives instead of from the perspective of health providers. The experiences shared can serve as a reference for promoting the health of perimenopausal women. The findings of the current study may help more perimenopausal women actively engage in improving their health. In addition, health providers should actively provide health knowledge by using women's values and encourage using modern technology to improve health self-monitoring behaviors. Overall, we should understand the two concerns of "evaluating health" and "remaining young" and consider the transition to menopause as a turning point in improving active health management.

\section{Acknowledgements}

I am sincerely grateful to all participants who contributed to the completion of this study by sparing their time and sharing their experiences with me. Without them, the research would not have been completed and published.

\section{References}

Adler, S. R., Fosket, J. R., Kagawa-Singer, M., McGraw, S. A., Wong-Kim, E., Gold, E., \& Sternfeld, B. (2000). Conceptualizing menopause and midlife: Chinese American and Chinese women in the United States. Maturitas, 35(1), 11-23.

Ambikairajah, A., Walsh, E., Tabatabaei-Jafari, H., \& Cherbuin, N. (2019). Fat mass changes during menopause: a metaanalysis. Am Journal Obstet Gynecol, 221(5), 393-409. e350. https://doi.org/10.1016/j.ajog.2019.04.023

Brown, L., Bowden, S., Bryant, C., Brown, V., Bei, B., Gilson, K. M., \& Judd, F. (2015). Validation and utility of the attitudes to ageing questionnaire: Links to menopause and well-being trajectories. Maturitas, 82(2), 190-196. https://doi.org/10.1016/j.maturitas.2015.06.042

Ko, C. F. (2006). The Geriatric and Nurturing Functions of Family: A Comparative Study of China, Japan, Taiwan, and the EU Member States. The NCCU Journal of Sociology, 38, 1-24.

Ding, L., Bai, Y. J., Ma, F., Zhu, H. P., Kong, L. J., \& Jiang, Y. J. (2018). The application of qualitative descriptive method in nursing research. World Latest Medicine Information, 18(76), 99-100.

Gartner Says Global End-User Spending on Wearable Devices to Total \$52 Billion in 2020. (2019, October 30). Newsroom Press Releases. Retrieved from https://www.gartner.com/en/newsroom/press-releases/2019-10-30-gartner-says-global-end-user-spending-o n-wearable-dev

Ginsberg, R. L., Tinker, L., Liu, J., Gray, J., Sangi-Haghpeykar, H., Manson, J. E., \& Margolis, K. L. (2016). Prevalence and correlates of body image dissatisfaction in postmenopausal women. Women Health, 56(1), 23-47. https://doi.org/10.1080/03630242.2015.1074636

Gracia, C. R., \& Freeman, E. W. (2018). Onset of the Menopause Transition: The Earliest Signs and Symptoms. Obstet Gynecol Clin North Am, 45(4), 585-597. https://doi.org/10.1016/j.ogc.2018.07.002

Graneheim, U. H., \& Lundman, B. (2004). Qualitative content analysis in nursing research: concepts, procedures and measures to achieve trustworthiness. Nurse Educ Today, 24(2), 105-112. https://doi.org/10.1016/j.nedt.2003.10.001 
Greendale, G. A., Huang, M., Cauley, J. A., Liao, D., Harlow, S., Finkelstein, J. S., \& Karlamangla, A. S. (2019) Trabecular bone score declines during the menopause transition: The study of women's health across the nation (swan). Journal Clin Endocrinol Metab. https://doi.org/10.1210/clinem/dgz056

Health Promotion Administration, Ministry of Health and Welfare, Taiwan, ROC. (2017). Adult preventive health. Retrieved from https://www.hpa.gov.tw/Pages/List.aspx?nodeid=189

Hoga, L., Rodolpho, J., Goncalves, B., \& Quirino, B. (2015). Women's experience of menopause: A systematic review of qualitative evidence. JBI Database System Rev Implement Rep, 13(8), 250-337. https://doi.org/10.11124/jbisrir-2015-1948

Ishizuka, B., Kudo, Y., \& Tango, T. (2008). Cross-sectional community survey of menopause symptoms among Japanese women. Maturitas, 61(3), 260-267. https://doi.org/10.1016/j.maturitas.2008.07.006

Islam, M. R., Gartoulla, P., Bell, R. J., Fradkin, P., \& Davis, S. R. (2015). Prevalence of menopausal symptoms in Asian midlife women: a systematic review. Climacteric, 18(2), 157-176. https://doi.org/10.3109/13697137.2014.937689

Lincoln, Y. S., \& Guba, E. G. (1985). Naturalistic inquiry. Beverly Hills, CA: Sage.

Lin, H. L., Hsiao, M. C., Liu, Y. T., \& Chang, C. M. (2013). Perimenopause and incidence of depression in midlife women: a population-based study in Taiwan. Climacteric, 16(3), 381-386. https://doi.org/10.3109/13697137.2012.707706

Luff, G. M., \& Gray, J. J. (2009). Complex messages regarding a thin ideal appearing in teenage girls' magazines from 1956 to 2005. Body Image, 6(2), 133-136.

Marlatt, K. L., Beyl, R. A., \& Redman, L. M. (2018). A qualitative assessment of health behaviors and experiences during menopause: A cross-sectional, observational study. Maturitas, 116, 36-42. https://doi.org/10.1016/j.maturitas.2018.07.014

McKinley, N. M., \& Lyon, L. A. (2008). Menopausal attitudes, objectified body consciousness, aging anxiety, and body esteem: European american women's body experiences in midlife. Body Image, 5(4), 375-380. https://doi.org/10.1016/j.bodyim.2008.07.001

Monteleone, P., Mascagni, G., Giannini, A., Genazzani, A. R., \& Simoncini, T. (2018). Symptoms of menopause - global prevalence, physiology and implications. Nat Rev Endocrinol, 14(4), 199-215. https://doi.org/10.1038/nrendo.2017.180

Namazi, M., Sadeghi, R., \& Behboodi Moghadam, Z. (2019). Social Determinants of Health in Menopause: An Integrative Review. International Journal Womens Health, 11, 637-647. https://doi.org/10.2147/ijwh.S228594

National Institutes of Health. (2017). What Is Menopause. Retrieved from https://www.nia.nih.gov/health/what-menopause

Sang, O. B. (n.d.). Wikipedia. Retrieved February 2, 2019, from https://zh.m.wiktionary.org/zh-hant/\%E6\%AD\%90\%E5\%B7\%B4\%E6\%A1\%91

Parand avar, N., Mosalanejad, L., Ramezanli, S., \& Ghavi, F. (2014). Menopause and crisis? Fake or real: Comprehensive search to the depth of crisis experienced: A mixed-method study. Glob Journal Health Science, 6(2), 246-255. https://doi.org/10.5539/gjhs.v6n2p246

Pearce, G., Thogersen-Ntoumani, C., \& Duda, J. (2014). Body image during the menopausal transition: a systematic scoping review. Health Psychol Rev, 8(4), 473-489. https://doi.org/10.1080/17437199.2013.848408

Reus, T. L., Brohem, C. A., Schuck, D. C., \& Lorencini, M. (2019). Revisiting the effects of menopause on the skin: functional changes, clinical studies, in vitro models and therapeutic alternatives. Mech Ageing Dev, 185, 111-193. https://doi.org/10.1016/j.mad.2019.111193

Reyhani, M., Kazemi, A., \& Keshvari, M. (2018). Rise and fall: two sides of a coin of middle aged women's perceptions of reproductive: a qualitative study. Arch Womens Ment Health, 21(4), 421-428. https://doi.org/10.1007/s00737-018-0815-4

Sandelowski, M. (2000). Whatever happened to qualitative description?. Res Nurs Health, 23(4), 334-340. https://doi.org/10.1002/1098-240x(200008)23:4<334::aid-nur9>3.0.co;2-g

Samargandy, S., Matthews, K. A., Brooks, M. M., Barinas-Mitchell, E., Magnani, J. W., Janssen, I., \& El 
Khoudary, S. R. (2020). Arterial stiffness accelerates within 1 year of the final menstrual period: The swan heart study. Arterioscler Thromb Vasc Biol, Atvbaha119313622. https://doi.org/10.1161/atvbaha.119.313622

Strehler, B. L., \& Mildvan, A. S. (1960). General theory of mortality and aging. Science, 132, 14-21. https://doi.org/10.1126/science.132.3418.14

Takahashi, T. A., \& Johnson, K. M. (2015). Menopause. Med Clin North Am, 99(3), 521-534. https://doi.org/10.1016/j.mcna.2015.01.006

World Health Organization. (2019). Life expectancy and causes of death. World Health Statistics 2019: $\begin{array}{lllll}\text { Monitoring health for the } & & \\ \end{array}$ https://www.who.int/gho/publications/world_health_statistics/2019/EN_WHS_2019_TOC.pdf

World Health Organization. (2009). Population of women by child-bearing age group and country. Retrieved from http://www.wpro.who.int/information_sources/databases/demographic tables/e Table 5.htm

World Health Organization. (1996). Technical Report Series 866. Geneva, Switzerland: Author. Retrived December 16, 2019, from https://apps.who.int/iris/handle/10665/41841

Yang, L. Q. (2003). Cultural Perspective of Appellation in Chinese. Journal of Baoding University, 2003(1), 65-67.

\section{Copyrights}

Copyright for this article is retained by the author(s), with first publication rights granted to the journal.

This is an open-access article distributed under the terms and conditions of the Creative Commons Attribution license (http://creativecommons.org/licenses/by/4.0/). 